\title{
Sustaining control of schistosomiasis mansoni in moderate endemicity areas in western Côte d'IVoire: a SCORE study protocol
}

Rufin K Assaré 1,2,3,4, Stefanie Knopp ${ }^{1,2,5}$, Nicaise A N'Guessan ${ }^{3}$, Ahoua Yapi ${ }^{3}$, Yves-Nathan T Tian-Bi ${ }^{3}$, Patrick K Yao ${ }^{3}$, Jean T Coulibaly 1,2,3,4, Mamadou Ouattara ${ }^{3}$, Aboulaye Meïté ${ }^{6}$, Alan Fenwick ${ }^{7}$ Eliézer K N'Goran ${ }^{3,4}$ and Jürg Utzinger ${ }^{1,2^{*}}$

\begin{abstract}
Background: Schistosomiasis is a parasitic disease that occurs in the tropics and subtropics. The mainstay of control is preventive chemotherapy with praziquantel. In Africa, an estimated 230 million people require preventive chemotherapy. In western Côte d'Ivoire, infections with Schistosoma mansoni are widespread. To provide an evidence-base for programme decisions about preventive chemotherapy to sustain control of schistosomiasis, a 5-year multi-country study with different treatment arms has been designed by the Schistosomiasis Consortium for Operational Research and Evaluation (SCORE) and is currently being implemented in various African settings, including Côte d'Ivoire.
\end{abstract}

Methods/Design: We report the study protocol, including ethics statement and insight from a large-scale eligibility survey carried out in four provinces in western Côte d'Ivoire. The study protocol has been approved by the ethics committees of Basel and Côte d'Ivoire. A total of 12,110 children, aged 13-14 years, from 264 villages were screened for S. mansoni using duplicate Kato-Katz thick smears from single stool samples. Among the schools with a S. mansoni prevalence of 10-24\%, 75 schools were selected and randomly assigned to one of three treatment arms. In each school, three stool samples are being collected from 100 children aged 9-12 years annually and one stool sample from 100 first-year students at baseline and in the final year and subjected to duplicate Kato-Katz thick smears. Cost and coverage data for the different intervention arms, along with environmental, political and other characteristics that might impact on the infection prevalence and intensity will be recorded in each study year, using a pretested village inventory form.

Discussion: The study will document changes in S. mansoni infection prevalence and intensity according to different treatment schemes. Moreover, factors that determine the effectiveness of preventive chemotherapy will be identified. These factors will help to develop reasonable measures of force of transmission that can be used to make decisions about the most cost-effective means of lowering prevalence, intensity and transmission in a given setting. The gathered information and results will inform how to effectively sustain control of schistosomiasis at a low level in different social-ecological contexts.

Trial registration: ISRCTN99401114 (date assigned: 12 November 2014).

Keywords: Schistosomiasis, Schistosoma mansoni, Control, Morbidity control, Preventive chemotherapy, Praziquantel, Prevalence, Intensity of infection, Côte d'Ivoire, SCORE

\footnotetext{
* Correspondence: juerg.utzinger@unibas.ch

'Department of Epidemiology and Public Health, Swiss Tropical and Public

Health Institute, P.O. Box, CH-4002 Basel, Switzerland

${ }^{2}$ University of Basel, P.O. Box, CH-4003 Basel, Switzerland

Full list of author information is available at the end of the article
}

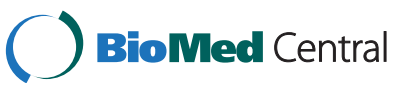

(C) 2014 Assaré et al.; licensee BioMed Central. This is an Open Access article distributed under the terms of the Creative Commons Attribution License (http://creativecommons.org/licenses/by/4.0), which permits unrestricted use, distribution, and reproduction in any medium, provided the original work is properly credited. The Creative Commons Public Domain Dedication waiver (http://creativecommons.org/publicdomain/zero/1.0/) applies to the data made available in this article unless otherwise stated. 


\section{Background}

\section{Burden and transmission of schistosomiasis, with an} emphasis on Schistosoma mansoni in Africa

Human schistosomiasis, a disease caused by chronic infection with parasitic trematodes of the genus Schistosoma, is endemic in 78 tropical and subtropical countries, 42 of which are located in Africa [1]. An estimated 779 million people are at risk of schistosomiasis, more than 230 million are infected, 120 million are symptomatic and 20 million suffer from severe and debilitating forms of schistosomiasis [2-5]. The burden of the disease is essentially concentrated in Africa, where more than $90 \%$ of the infections worldwide occur [5-7]. Schistosomiasis is intimately connected with poverty, and hence, the disease delays the social and economic development in endemic countries [5,8-10].

The life cycle of schistosomiasis involves a phase of sexual reproduction by adult schistosome worms in the definitive human host, and an asexual phase in the intermediate host, a specific freshwater snail. In Côte d'Ivoire, for example, Biomphalaria pfeifferi is the only intermediate host snail for Schistosoma mansoni [11]. From the snail, cercariae are released into the surrounding water and can invade humans through the skin. Infection with $S$. mansoni causes intestinal schistosomiasis. Typical symptoms include blood in the stool, (bloody) diarrhoea, chronic or intermittent abdominal pain, anaemia, general fatigue, weight loss, hepatomegaly, splenomegaly and marked eosinophilia $[8,12]$. Moreover, chronic infection can impair children's physical and cognitive development and nutritional status [13]. Associations of intestinal schistosomiasis with hepatitis, acquired immunodeficiency syndrome (AIDS) and malaria hypertension have been reported [14-16].

Several factors contribute to the spread of schistosomiasis. Demographic features, including age, gender, ethnicity and socioeconomic status have a strong influence on the spatial distribution of schistosomiasis, particularly S. mansoni $[17,18]$. Tourism, construction and operation of water resource developments (i.e. irrigation schemes and dams) are associated with higher risks of S. mansoni, explained by the creation of favourable conditions for intermediate host snails and higher frequencies of humanwater contacts $[5,19,20]$. It is estimated that more than 100 million people at risk of schistosomiasis live in irrigation schemes or in close proximity to reservoirs of large dams [5]. Intense rainfall and flooding might be responsible for the reintroduction of intermediate host snails to areas from which schistosomiasis had previously been eliminated [21].

\section{Schistosomiasis control in Africa}

According to the World Health Organization (WHO), comprehensive schistosomiasis control programmes should include treatment of at-risk groups, provision of clean water, adequate sanitation, hygiene education and snail control [1]. The current mainstay of control is preventive chemotherapy - that is the periodic administration of the antischistosomal drug praziquantel to entire atrisk populations without prior diagnosis. The goal is to cover at least $75 \%$ of those at risk of schistosomiasis by preventive chemotherapy in 2020 [7]. The frequency of preventive chemotherapy is guided by infection prevalence in specific age groups. In areas where the prevalence of Schistosoma infection in school-aged children (5-14 years) is $50 \%$ or higher, entire communities should be treated once every year; if the prevalence is between $10 \%$ and $50 \%$, treatment is focussed on school-aged children with a frequency once every two years; if the prevalence is below 10\%, school-aged children should be treated twice, at school entry and again before they finish schooling [22,23]. In Africa, approximately 35.5 million people were treated with praziquantel in 2012 [1]. This estimate accounts for a coverage of only $13.6 \%$ of schoolaged children. Hence, concerted efforts are needed to massively scale-up preventive chemotherapy to reach the $75 \%$ coverage goal by the year 2020. In Côte d'Ivoire, where both $S$. mansoni and S. haematobium are endemic and many people suffer from intestinal or urogenital schistosomiasis [17,24-29], no large-scale preventive chemotherapy programme was in place prior to the onset of this study in 2011 [28,30,31].

\section{Operational research for schistosomiasis control}

Further up-scaling of schistosomiasis control in the years to come will not only need political commitment, national strategic plans, dedicated development partners, functioning health systems and community volunteers, but will also involve major costs. To assess which strategy of preventive chemotherapy will provide the best balance in terms of reduction in prevalence and intensity of schistosome infection in school-aged children on one hand, and costs on the other hand, the Schistosomiasis Consortium for Operational Research and Evaluation (SCORE; http://score.uga.edu/) designed a series of largescale, multi-country intervention studies. In response to a request for proposals to gain and sustain control of schistosomiasis in Africa, several investigators from Africa, in partnership with colleagues from Europe and the United States of America, put forward their ideas. The proposals were evaluated by a panel of experts against predefined criteria. Initially, three projects were selected under the heading "Sustaining control of schistosomiasis", focusing either on S.mansoni (two projects; Côte d'Ivoire and Kenya) or S. haematobium (one project; Niger). The overarching goal is to evaluate alternative approaches to preventive chemotherapy in areas with moderate prevalence of infection at baseline (10-24\% in school-aged children). 
Of note, the sustaining schistosomiasis haematobia project in Niger has been terminated after two years due to an issue with the randomisation of study villages.

Here, we summarise the relevant part of a harmonised study protocol that is being followed by partners conducting the sustaining control of schistosomiasis mansoni studies in Côte d'Ivoire and Kenya. The field and laboratory procedures for the sustaining S. mansoni control project in moderate endemicity areas of Côte d'Ivoire will be presented in greater detail, including results of the initial eligibility survey, which guided the selection of 75 communities or villages for subsequent treatment interventions.

\section{Goal, aims and objectives}

The goal of the SCORE projects aiming at sustaining control of schistosomiasis at a low level is to generate an evidence-base for programme decisions about preventive chemotherapy-based approaches to sustain the control of $S$. mansoni infections. The studies will determine which strategy for preventive chemotherapy provides the best balance in terms of cost and the reduction in prevalence and intensity of infection in school-aged children after four years of intervention. The studies are designed to answer the following question: How can we sustain control of $S$. mansoni in communities/villages with a moderate endemicity level (prevalence of $10-24 \%$, as assessed by a single stool examination with duplicate Kato-Katz thick smears)? Specifically, we are addressing the following research questions:

- What combination of annual school-based treatment (SBT) and "drug holidays" yields the best outcomes for the lowest cost?

- What are the factors that determine the effectiveness of preventive chemotherapy?

- Can reasonable measures of force of transmission be developed that can be utilised to make decisions about the most cost-effective means of lowering prevalence, intensity and transmission in a given setting?

\section{Methods/Design \\ Study design}

The SCORE sustaining schistosomiasis control studies are designed as randomised intervention trials with three study arms. Each arm comprises 25 communities or villages. Hence, the studies will include 75 communities per country. Communities will be provided with various combinations of SBT and "drug holidays" over a 4-year period, followed by final data collection, analysis and dissemination of results in the fifth year. The intervention arms in the sustaining schistosomiasis control studies are designed as shown in Figure 1. In brief:

- schools of arm A will receive annual SBT for four years;

- schools of arm B will receive SBT in the first two years, followed by "drug holidays"; and

- schools of arm C will receive SBT in years 1 and 3, alternated by "drug holidays" in years 2 and 4 .

Preventive chemotherapy with praziquantel is being provided as single oral dose of $40 \mathrm{mg} / \mathrm{kg}$, using a dose pole. Standard praziquantel treatment exclusion criteria apply [22]. No treatment will be provided during "drug holidays" and no parasitological data are collected in those years. During SBT, praziquantel will be administered by trained teachers to all school-going children. Children in all schools in the community will be treated, and hence, children attending schools not otherwise involved in the study will also receive treatment. Any time SBT will take place, additional efforts will be made to enhance treatment coverage, such as community sensitization and mobilization efforts, radio announcements, and other means of information, education and communication (IEC) strategies. Non-school attendees who span the same age range as school-going children will also be invited for treatment. No other major treatment strategies outside the education sector venue will be implemented. The school attendance rates and treatment coverage will be documented throughout the study.

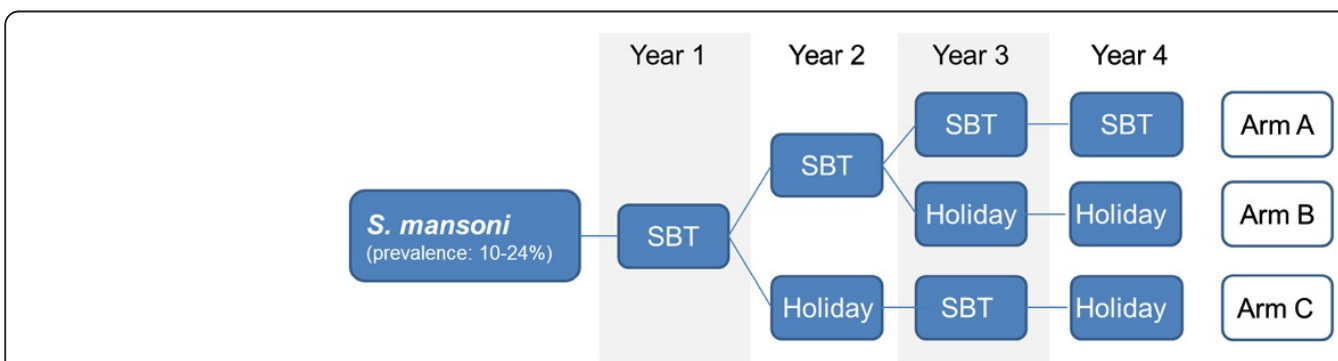

Figure 1 Study arms for the sustaining control of Schistosoma mansoni studies in moderate endemicity areas (prevalence: 10-24\%). SBT, school-based treatment; Holiday, no drug delivery. 


\section{Justification of the number of intervention arms and participants}

The protocol for the sustaining schistosomiasis control studies was developed through a series of expert consultations, facilitated by the SCORE secretariat and its scientific advisory board. The decision to choose three intervention arms for the current studies took into consideration formal sample size calculation and operational feasibility. For sample size calculation, it was assumed that the treatment interventions will reduce Schistosoma prevalence in moderate endemicity areas from 25\% to $10 \%$. Analyses determined the minimum effect size that may be detected with $90 \%$ power for a 2 -sided $\alpha=0.05$ level test as a function of the number of children $m$ tested per village, the number $n$ of villages sampled per treatment, the overdispersion parameter $\varphi$, and the correlation $\rho$ between observations in year 1 at baseline and in year 4 at the end of the study. The calculations revealed that studying 20 communities or schools per arm and evaluating 100 individuals per school would result in minimum effect sizes of $5-12 \%$ with or without overdispersion. This minimum effect size was deemed reasonable. To further increase the chance of detecting differences between the interventions arms, the number of the units of interventions, and hence, the number of schools, was increased to 25 per arm. Taken together, the trial protocol asked to examine 100 children aged 9-12 years every year whenever drug intervention will be implemented as primary outcome. Additionally, 100 first-year students will be examined in years 1 and 5 .

\section{Eligibility of study communities}

Sustaining schistosomiasis control studies will include 75 communities with an initial S. mansoni prevalence of $10-24 \%$. Selection of these large numbers of communities has been determined through a rapid appraisal eligibility survey. A single stool sample from each of 50 children aged 13-14 years has been subjected to duplicate Kato-Katz thick smears [32,33]. Additional criteria applied for eligibility determination are as follows. First, a study community must have a primary school, because the arms of the study are school-based and every participating community must be eligible to be randomised to any of the study arms. However, it is permitted that a study community may have more than one school. If two nearby communities have schools with less than 100 children per school but they are similar in terms of ecology and socioeconomic status, they can be combined for purposes of this study and be considered as a single study community. Second, two nearby communities that share water sources and/or whose schools have overlapping catchment areas will not be considered separate villages for the purposes of this study; one of the two schools will be chosen. Third, there is no pre-set population requirement for the size of a community, as long as it includes at least 100 children aged 9-12 years who attend school. Fourth, preference is for settings that have not recently been subjected to preventive chemotherapy targeting schistosomiasis. If communities have been previously treated, historic treatment data should be included where available. Fifth and finally, to the extent possible, study communities should be as similar as possible in characteristics that could affect transmission dynamics, including, for example, a history of past treatment and the availability of water sources.

\section{Eligibility of study participants}

For the eligibility study to rapidly identify the 75 communities with a baseline prevalence of $10-24 \%$, children were eligible to participate if they were 13 or 14 years old and provided an informed consent sheet signed by their parents. In the baseline and the yearly follow-up surveys conducted to assess the change in prevalence and intensity of Schistosoma infection in each intervention arm, children aged 9-12 years who provide a written informed consent from their parents will be included. Additionally, in years 1 and 5, first-year students will provide written informed consent from their parents and will participate in the study.

\section{Details of the sustaining S. mansoni control study in western Côte d'Ivoire \\ Study area and population}

The sustaining S. mansoni control study in Côte d'Ivoire is being conducted by a team of researchers from the Université Félix Houphouët-Boigny, who work in close collaboration with the Programme National de Lutte contre la Schistosomiase, les Géohelminthiases et la Filariose Lymphatique (PNL-SGF) at the Ministry of Health and Public Hygiene, the 'Centre Suisse de Recherches Scientifiques en Côte d'Ivoire (CSRS), all based in Abidjan, and the Swiss Tropical and Public Health Institute (Swiss TPH) in Basel, Switzerland.

The study area is located in western Côte d'Ivoire in the four regions Cavaly, Guemon, Haut-Sassandra and Tonkpi (Figure 2). The area was chosen because it is a well known S. mansoni focus [25] and our teams conducted schistosomiasis research there since the mid1990s, including treatment of individuals found positive upon Kato-Katz examination [17,24,28,29,34-37]. Cavaly, Guemon and Tonkpi regions are located west of the Sassandra River and belong to the district des Montagnes. Ten departments of this district are included in our study: Bangolo, Biankouma, Danané, Douékoué, Facobly, Guiglo, Kouibly, Man, Sipilou and Zoukougbeu. The district des Montagnes is a mountainous area with an average altitude ranging between $300 \mathrm{~m}$ and slightly above $1,000 \mathrm{~m}$. The climate is humid tropical with two seasons. The rainy 


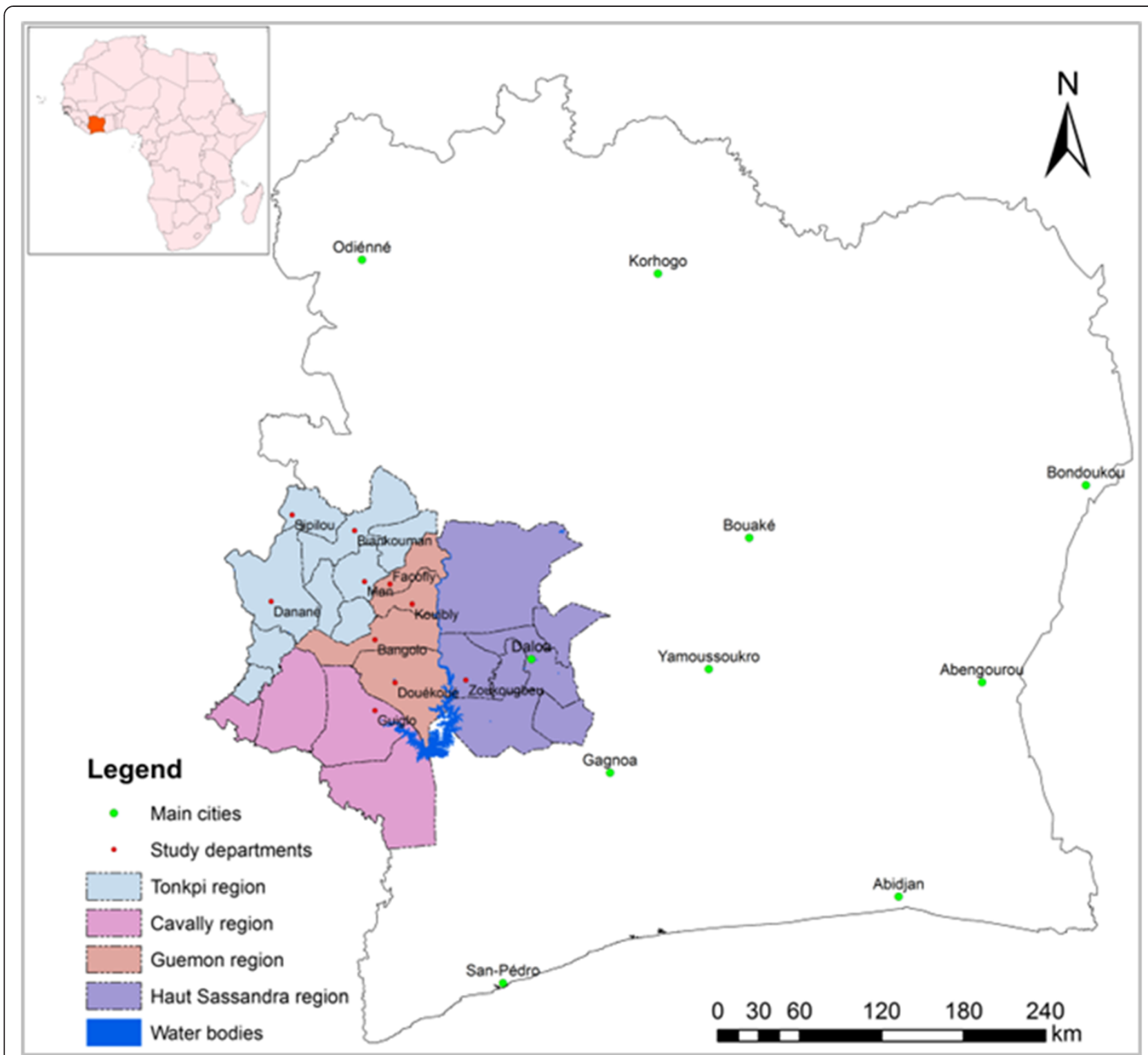

Figure 2 Map of Côte d'Ivoire with the four study regions in the western part where the SCORE sustaining S. mansoni control project is being implemented.

season usually lasts from March to October. The HautSassandra region is located East of the Sassandra River. Zoukougbeu is the only department of that region which is included in our study. Here, the average altitude ranges between $200 \mathrm{~m}$ and $300 \mathrm{~m}$. The climate is sub-equatorial, characterised by two rainy seasons. The long rainy season occurs from March to July and the short rainy season from September to October.

According to the national population census carried out in 1998 (the most recent census at the time of writing the current piece), the total population in the study area is 1.5 million people (unpublished data; Institut National de la Statistique en Côte d'Ivoire). Most people belong to one among the four ethnic groups: Bété, Guéré, Wobé and Yacouba. People are mainly engaged in subsidence farming (cassava, maize, plantain and rice). There is also production of cash crops (coffee and cocoa) and a small forestry industry in the town of Man [38].

The annual rainfall in the study area varies between 1,100 and 2,000 $\mathrm{mm}$. The vegetation is composed of two types of forests (semi-deciduous and evergreen mountain forest). The average annual temperature is around $26^{\circ} \mathrm{C}$.

\section{Selection and randomisation of study villages}

The 75 villages with a S. mansoni prevalence of $10-24 \%$ in western Côte d'Ivoire were identified as follows. First, 
our team organised a series of meetings with health and education authorities in the four study regions. The purpose and procedures of the study were explained and a total of 264 communities fulfilling the following criteria were identified: (i) village has a school attended by at least 100 children aged 9-12 years in grades $2-5$ and 50 children aged at least 13 years in grades 4-6; (ii) village and school had no recent history of preventive chemotherapy using praziquantel against schistosomiasis (within the past 12 months); (iii) village is accessible also in the rainy season; and (iv) it is safe for our teams to work in the village. The latter issue was a real concern, as Côte d'Ivoire suffered from a decade-long political unrest that culminated in armed conflict and war in late 2010/early 2011 [39]. Before the onset of the surveys in each school, we conducted a brief interview with the school teachers to assess the selectability of the villages, according to the aforementioned criteria. Then, schoolchildren in grades 1-6 were informed about the mode of transmission of S. mansoni, its health impact and the importance of the current project. Children aged 13 or 14 years were randomly selected from grades 4-5 until the number of children reached 50 . In settings where less than 50 children aged 13-14 years were present, the sample was completed with 12-year-old children, but these children will not be enrolled in the subsequent randomised controlled trial.

Children were asked to provide a written informed consent from their parents or legal guardians. Children with written informed consent were supplied with plastic containers to collect a small amount of their own early morning stool specimen. Collection containers were labelled with unique identification numbers. The name, sex, age and school grade of each child were recorded.

Stool samples were transferred to the Centre Hospitalier Regional de Man for parasitological examination. From each stool sample, duplicate Kato-Katz thick smears were prepared on microscope slides using $41.7 \mathrm{mg}$ templates [32,33]. After allowing the slides to clear for at least $60 \mathrm{~min}$, they were examined under a microscope by experienced laboratory technicians for the presence of S. mansoni and soil-transmitted helminths (i.e. Ascaris lumbricoides, hookworm and Trichuris trichiura).

The prevalence of S. mansoni was calculated for each school. A total of 12,110 children submitted a stool sample that was subjected to duplicate Kato-Katz thick smears. The prevalence at the unit of the school in the eligibility survey ranged from $0 \%$ to $100 \%$ (Figure 3 ). In brief, among the 264 schools, 157 (59.5\%) had a S. mansoni prevalence above 24\%, 78 (29.5\%) schools had a prevalence ranging between $10 \%$ and $24 \%$, whilst the remaining 29 schools (11.0\%) had a prevalence below $10 \%$. As shown in Figure 4, most of the villages meeting the sustaining control prevalence range (i.e. 10-24\%) that were ultimately selected $(n=75)$ are located in the Guemon region. The schools were randomly assigned to three intervention arms using a computer-based randomisation procedure conducted by an independent statistician.

\section{Data collection in the main study \\ Collection of stool samples and administration of a questionnaire}

At the beginning of the main activities of the sustaining S. mansoni control study in the western part of Côte

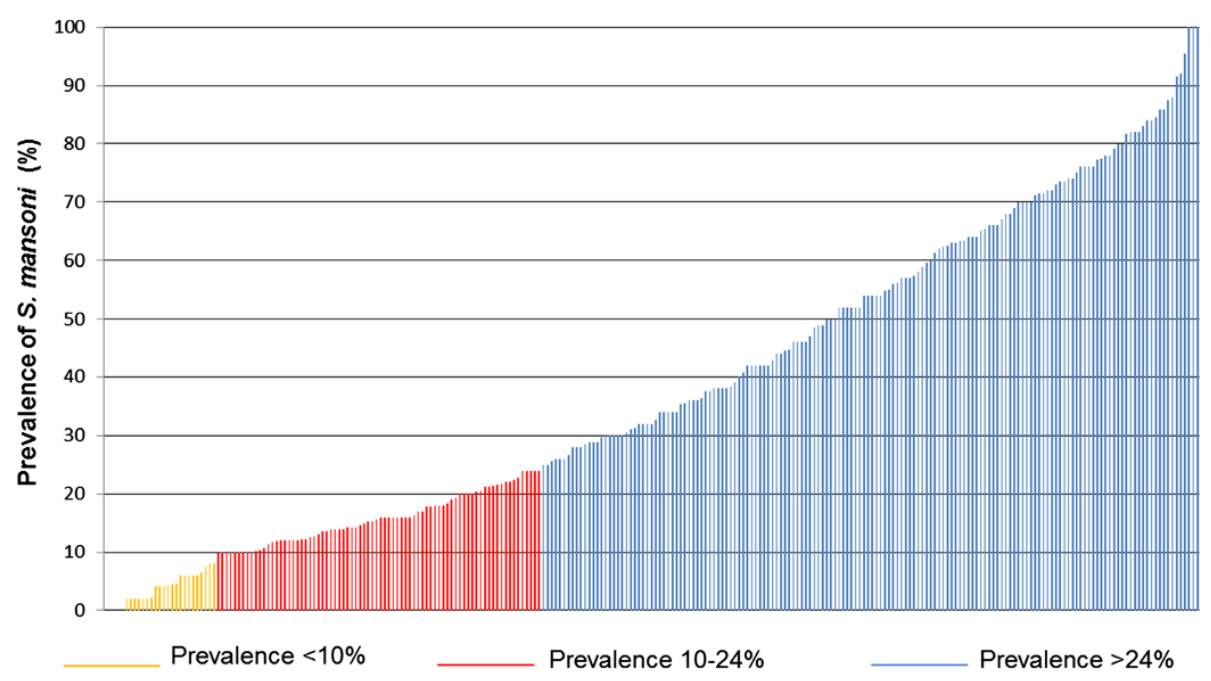

Figure 3 Range of prevalence of S. mansoni infection in the 264 villages screened in western Côte d'Ivoire to identify moderate S. mansoni endemicity areas (10-24\%). At the unit of the school, we examined 50 children aged 13-14 years with duplicate Kato-Katz thick smears from a single stool sample. 


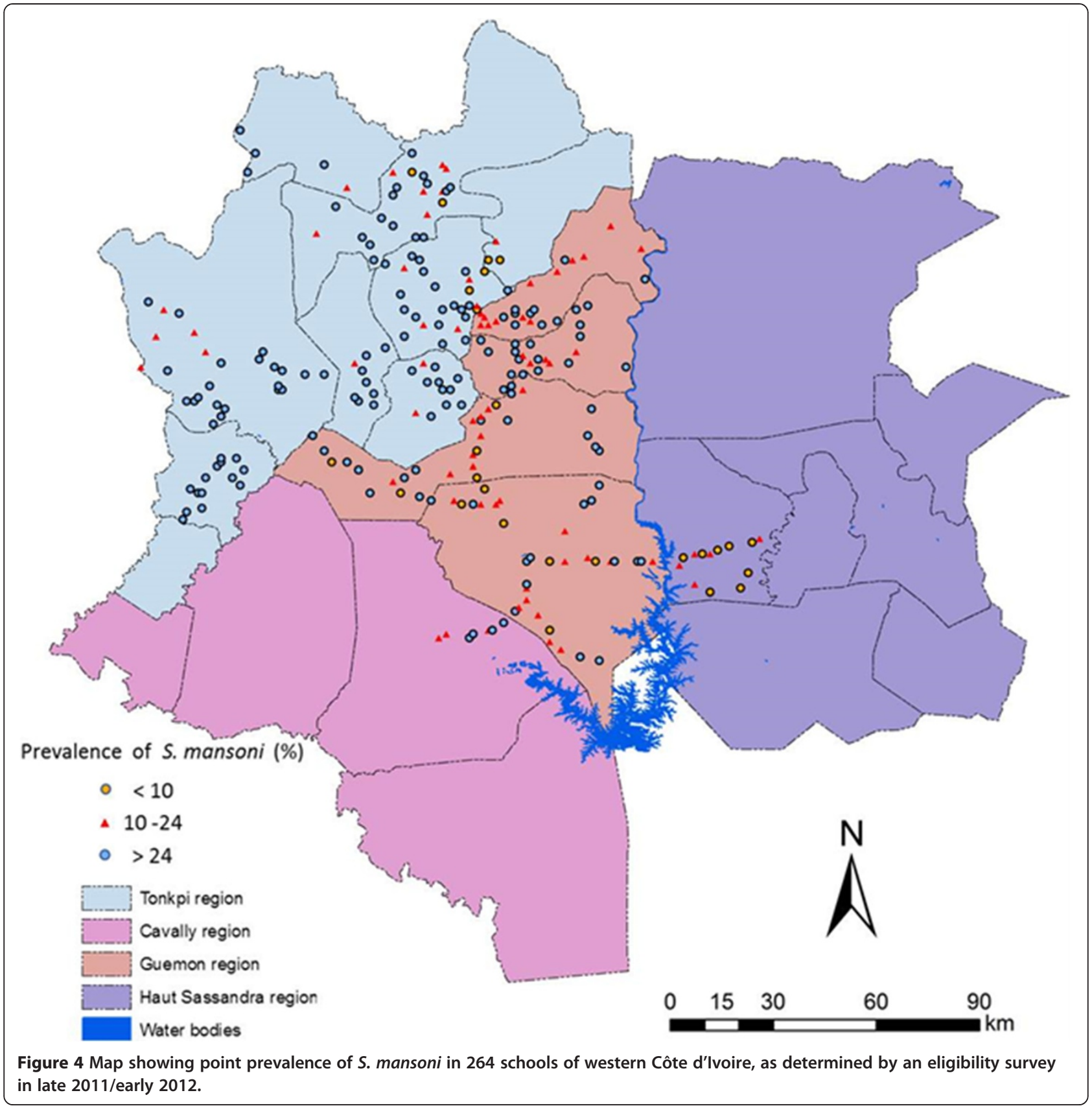

d'Ivoire, a small designated team informed district and village authorities and children's parents. Detailed information was provided about the forthcoming crosssectional parasitological and questionnaire surveys. Each year, shortly before the annual parasitological survey, teachers will be re-informed about the purpose and procedures of the study. Teachers assist by preparing class lists, including name, age, sex and school grade. In each school, children aged 9-12 years are enrolled from grades 2-6 until 100 pupils will be reached. Moreover, at baseline and in the final year of the study, 100 pupils will be randomly selected from the class list of grade 1 and their age will be recorded.

Before sample collection commences, the study is explained in lay terms to the selected children and they are invited to provide three stool samples over consecutive days. Stool samples are collected in $125 \mathrm{ml}$ plastic containers. Children are asked to return the containers within an hour, filled with an apricot-sized portion of their own stool. We collect the containers and label them with individual IDs. The stool collection procedure is repeated over three consecutive days. Children without 
written consent from their parents and those who are unable to produce at least two stool samples are withdrawn, but they receive praziquantel treatment as the other children in the same village. For final analysis those children who have written consent and results from at least four Kato-Katz thick smears are included.

Upon visiting the school by our team, the community leader is contacted and interviewed with a pre-tested questionnaire to record characteristics of demography, main activities, health system, water contact sites, and sources of water and sanitary facilities in the village. Demographic information includes the number of households and total population. The health system is characterised by accessibility to health infrastructures, and availability of praziquantel against schistosomiasis and artemisinin-based combination therapy (ACT) against malaria. Information pertaining to water contact sites comprises the number of stagnant and non-stagnant freshwater bodies. The questionnaire also allows determining which type of water the population uses for drinking, bathing and cleaning. We also assess which type of sanitary facilities the population uses (i.e. pit latrine, ventilated improved pit latrine, toilet or any other kind of facilities).

Overall, the plan is to collect 22,500 stool samples from children aged 9-12 years and 7,500 stool samples from first-grade children at baseline (year 1) and at the end of the study (year 5). In years 2, 3 and 4, a total of 15,000 stool samples will be collected from children aged 9-12 years. Children on "drug holidays" will not be subjected to stool examination.

\section{Laboratory procedures to assess S. mansoni infection}

Fresh stool samples are transferred to central laboratories at the hospitals of Bangolo, Biankouma, Danané, Douékoué, Guiglo, Kouibly and Man. The stool samples are subjected to the Kato-Katz method [32,33]. In brief, duplicate Kato-Katz thick smears are prepared from each sample using standard $41.7 \mathrm{mg}$ templates. After a clearing time of at least $60 \mathrm{~min}$, the thick smears will be examined under a microscope by experienced laboratory technicians. Eggs of S. mansoni and soil-transmitted helminths (A. lumbricoides, hookworm and T. trichiura) are counted and recorded for each species separately. For quality control, $10 \%$ of the slides are randomly selected and re-examined by a senior microscopist. The results are compared with the results of the first examination by the team. Slides identified with discrepant results (e.g. S. mansoni egg-positive vs. egg-negative or difference of S. mansoni egg counts of more than 20\%) are reexamined until agreement has been reached. Given the large number of slides processed in the eligibility survey, parts of the slides were transferred to Abidjan and were examined microscopically within a maximum of
3 months after stool collection. All record sheets will be transferred to the Université Félix Houphouët-Boigny, where data entry, cleaning and database management take place.

\section{SBT and assessment of coverage}

District and community medical personnel are associated with the SBT in Côte d'Ivoire. Teachers and community health workers are trained to sensitize the communities, to administer drugs to the children and to monitor adverse events. Different sensitization tools are implemented such as radio and television announcements, along with other IEC strategies.

During SBT, praziquantel is administered by trained teachers to all children attending school. Children in all schools in the community are treated, even if the school is not among the 75 schools where children are being tested. Efforts are made to reach out to non-enrolled children to enhance treatment coverage.

Treatment is supervised by physicians and implemented by trained school teachers. Praziquantel tablets are delivered using a WHO dose pole [40]. Children are monitored for adverse events for 4 hours after treatment and, if need be, appropriate medical action is taken. Treatment will be led by the PNL-SGF, and supported by staff from the Programme National de Santé Scolaire et Universitaire (PNSSU). Financial support to facilitate treatment is provided by SCORE, while praziquantel tablets are supplied by the Schistosomiasis Control Initiative (SCI).

\section{Data collection, management and statistical analysis}

In the eligibility and baseline surveys, data are collected on paper form, but then, starting at year 2, smartphones have been utilised for data collection in the field and laboratory. Data cleaning and management is done by a designated database manager (PKY) at the Université Félix Houphouët-Boigny in Abidjan. Demographic and parasitological data directly entered in smartphones are uploaded to a database maintained on a central server (Open Data Kit) hosted by the SCORE secretariat at the Task Force for Global Health in Atlanta, United States of America. Data from questionnaire records will be entered in Microsoft Excel (2010 Microsoft Corporation). Statistical analyses will be carried out in STATA version 12 (StataCorp.; College Station, TX, USA). The primary outcome will be the change in prevalence and intensity of S. mansoni infection in the cohort of 9- to 12-yearold children over the four years of intervention. For each year, prevalence and infection intensity data will be calculated as described below. The results from the different study arms will be compared on an annual basis and at the end of the 4-year intervention period.

Each child with at least one S. mansoni egg identified in at least one of the Kato-Katz thick smears will be 
considered as positive. Eggs per gram of stool (EPG) will be determined for each child by calculating the arithmetic mean S. mansoni egg counts from all Kato-Katz thick smear readings and by multiplication with a factor 24. The S. mansoni infection intensity will be categorised according to WHO guidelines into light infection (1-99 EPG), moderate infection (100-399 EPG) and heavy infection ( $\geq 400$ EPG) [22].

School attendance rate will be documented throughout the study. The treatment coverage will be determined by (i) calculating the percentage of pupils treated among the total children registered in the school and (ii) calculating the percentage of school-aged children not attending school who are treated according to data from community health workers.

To guarantee the privacy of individuals, a separate and confidential file will be kept, detailing names against ID numbers. All data will be stored in purpose-built MS Excel files with no names but only ID numbers and will be kept by the data manager at the Université Félix Houphouët-Boigny. A safety copy will be stored in a secured locker. Only authorized persons will have access to the data within the context of the project, and the data will be backed-up regularly and safely. In addition, all work stations of data entry clerks will be protected by case-sensitive passwords and there will be no sharing of any account or password information between staff and other individuals not concerned with the project. When discussing or showing the results of analyses in public venues, the information will always be reported at an aggregate level so that individual participants cannot be identified.

\section{Protocol review and ethical clearance}

The study protocol has been approved by the institutional research commissions of Swiss TPH in Basel and CSRS in Abidjan. Ethical approval was obtained from the ethics committees in Basel (reference no. EKBB 279/10; Basel, 21 October 2010) and Côte d'Ivoire (reference no. 1994 MSHP/CNER; Abidjan, 5 May 2010). The trial is registered at controlled-trials.com (identifier: ISRCTN99401114; date assigned: 12 November 2014). Informed consent is obtained from parents or legal guardians of all pupils involved in the study. Children are treated with praziquantel (40 $\mathrm{mg} / \mathrm{kg}$ ) using a dose pole [40] in the frame of SBT. Efforts will be made to reach out to non-enrolled children.

The results of this study may be published, but subjects' names or identities will not be revealed. Records will remain confidential and the results of tests will be codified to prevent association with participants' names. Data entered into computerized files will be accessible only by authorized personnel directly involved in the study. Subject-specific information will be provided to medical personnel only with the subject's permission.

\section{Discussion}

Human schistosomiasis is a chronic and debilitating disease responsible for an estimated global burden of 3.3 million disability-adjusted life years [41]. In Africa, 230 million people currently require preventive chemotherapy [4]. The goal set by the WHO for the year 2020 is to treat at least $75 \%$ of school-aged children at risk of schistosomiasis with praziquantel as the only drug [7]. Various partners, institutions and pharmaceutical companies have agreed in the London Declaration of 2012 that they will contribute to achieving this goal with donation of praziquantel and other support to facilitate and sustain drug administration at large scale [42]. The SCORE study described here will provide an evidencebase for programme decisions about the type and frequency of preventive chemotherapy that is required to sustain control of schistosomiasis mansoni in areas where the baseline prevalence of infection ranges between $10 \%$ and $24 \%$. The study will show for well characterised settings across Africa which treatment scheme (yearly treatment of school-aged children, or treatment interspaced by holidays) will yield the best result and at what cost. Moreover, factors that determine the effectiveness of large-scale deworming will be identified. These factors will help to develop measures of force of transmission that can be utilised to make decisions about the most cost-effective means of lowering the prevalence and intensity of Schistosoma infection and the force of the transmission in a given setting. The data generated might shape future treatment schedules to sustain the control of schistosomiasis at low level elsewhere in subSaharan Africa and perhaps in Asia and Latin America where schistosomiasis also remains endemic, in preparation for a move to eliminate this disease in suitable locations.

In western Côte d'Ivoire, infections with S. mansoni are common $[17,24,34]$ but until the mid-1990s, the extent of endemicity was not well understood. Some control efforts had been implemented in the 2000s, but due to a decade-long socio-political crisis, control had been interrupted $[28,39]$. The large eligibility study conducted to select 75 villages with a moderate $S$. mansoni prevalence (10-24\%) clearly revealed that S. mansoni in the western part of Côte d'Ivoire is rampant; among 264 schools screened, 157 (59.5\%) had a S. mansoni prevalence above $24 \%$, while 78 schools $(29.5 \%)$ were in the desired prevalence range of $10-24 \%$ and only 29 schools (11.0\%) had a prevalence below $10 \%$. The eligibility survey employed an insensitive diagnostic approach (i.e. duplicate Kato-Katz thick smears based on a single stool sample). Had more intensive sampling and a more sensitive diagnostic method been employed (e.g. three stool samples subjected to triplicate Kato-Katz per stool sample or a point-of-care circulating cathodic antigen 
(POC-CCA) urine cassette test), a much higher overall prevalence of $S$. mansoni would have been found [43-47].

In order to respect World Health Assembly (WHA) resolution 54.19 endorsed in May 2001, which emphasises preventive chemotherapy targeting school-aged children to control morbidity [48], and in view of a more ambitions WHA resolution 65.21 put forth in May 2012, the new declared goal is to move from morbidity control to elimination of schistosomiasis [33,49]. Hence, authorities of Côte d'Ivoire have established the PNL-SGF in June 2007 [28]. Hand-in-hand with the SCORE sustaining schistosomiasis control operational research study reported here, the national schistosomiasis control programme was reinforced, with additional support from SCI. This study will provide data that may be used by SCORE, SCI, WHO and other partners to deploy the best tools and strategies to control morbidity due to schistosomiasis, and thus contribute to the reduction of poverty in schistosomiasis-endemic countries.

\section{Competing interests}

The authors declare that they have no competing interests.

\section{Authors' contributions}

SK, JTC, EKN and JU wrote the original SCORE Schistosoma mansoni sustaining control in Côte d'Ivoire protocol. RKA, NAN, AY, YNTTB, JTC, MO and EKN performed the eligibility survey. AM is responsible for community sensitization and mass drug administration, supported by AF. PKY managed data entry, cleaning and preparation of the database for statistical analysis. RKA, SK and JU wrote the first draft of the manuscript and revised the piece in light of the editors' and referees' comments and suggestions. All authors read and approved the final version of the paper prior to submission.

\section{Acknowledgements}

We are grateful to the members of the SCORE secretariat and advisory committee for reviewing our study, their advice, input and support of our work. We are grateful to Dr. Jan Hattendorf and Ms. Yingsi Lai from the Swiss Tropical and Public Health Institute for the randomisation of the schools and help with the mapping, respectively. We thank the technicians from different institutions of Côte d'Ivoire for their support in the field and the laboratory, particularly Mr. Laurent K. Lohourignon and Mr. Raphael G. Diabré. We are grateful to the health, education and village authorities of the regions of Cavaly, Guemon, Haut-Sassandra and Tonkpi for their contribution. We acknowledge teachers, students and parents for their participation in the study. We thank the team of the Laboratoire de Zoologie et de Biologie Animale at the Université Félix Houphouët-Boigny for their support in the field and in the laboratory. We are grateful to Prof. Bassirou Bonfoh, Director-General of the Centre Suisse de Recherches Scientifiques en Côte d'Ivoire for his support.

\section{Funding}

Our study is funded by the Bill \& Melinda Gates Foundation through the Schistosomiasis Consortium for Operational Research and Evaluation (SCORE) based at the University of Georgia in Athens, United States of America (sub-award no. RR374-053/4893196). Praziquantel tablets for schistosomiasis treatment are donated by the Schistosomiasis Control Initiative (SCI) based at Imperial College London, United Kingdom.

\section{Author details}

'Department of Epidemiology and Public Health, Swiss Tropical and Public Health Institute, P.O. Box, CH-4002 Basel, Switzerland. ' University of Basel, P.O. Box, $\mathrm{CH}-4003$ Basel, Switzerland. ${ }^{3}$ Unité de Formation et de Recherche Biosciences, Université Félix Houphouët-Boigny, 22 BP 770, Abidjan 22, Côte d'Ivoire. ${ }^{4}$ Centre Suisse de Recherches Scientifiques en Côte d'Ivoire, 01 BP 1303, Abidjan 01, Côte d'Ivoire. ${ }^{5}$ Wolfson Wellcome Biomedical Laboratories, Department of Life Sciences, Natural History Museum, Cromwell Road,
London SW7 5BD, UK. ${ }^{6}$ Programme National de Lutte contre la Schistosomiase, les Géohelminthiases et la Filariose Lymphatique, Ministère de la Santé et de I'Hygiène Publique, 06 BP 6394, Abidjan 06, Côte d'Ivoire. ${ }^{7}$ Schistosomiasis Control Initiative, Department of Infectious Disease Epidemiology, Faculty of Medicine, Imperial College London, VB1 Norfolk Place, St. Mary's Campus, London W2 1PG, UK.

Received: 26 August 2014 Accepted: 10 December 2014 Published: 17 December 2014

\section{References}

1. WHO: Schistosomiasis: number of people receiving preventive chemotherapy in 2012. Wkly Epidemiol Rec 2014, 89:21-28.

2. Chitsulo L, Engels D, Montresor A, Savioli L: The global status of schistosomiasis and its control. Acta Trop 2000, 77:41-51.

3. Steinmann P, Keiser J, Bos R, Tanner M, Utzinger J: Schistosomiasis and water resources development: systematic review, meta-analysis, and estimates of people at risk. Lancet Infect Dis 2006, 6:411-425.

4. Vos T, Flaxman AD, Naghavi M, Lozano R, Michaud C, Ezzati M, Shibuya K, Salomon JA, Abdalla S, Aboyans V, Abraham J, Ackerman I, Aggarwal R, Ahn SY, Ali MK, Alvarado M, Anderson LM, Andrews KG, Atkinson C, Baddour LM, Bahalim AN, Barker-Collo S, Barrero LH, Bartels DH, Basáñez MG, Baxter A, Bell ML, Benjamin EJ, Bennett D, Bernabé E, et al: Years lived with disability (YLDs) for 1160 sequelae of 289 diseases and injuries 1990-2010: a systematic analysis for the Global Burden of Disease Study 2010. Lancet 2012, 380:2163-2196.

5. Colley DG, Bustinduy AL, Secor WE, King CH: Human schistosomiasis. Lancet 2014, 383:2253-2264.

6. Utzinger J, Raso G, Brooker S, de Savigny D, Tanner M, Ørnbjerg N Singer BH, N'Goran EK: Schistosomiasis and neglected tropical diseases: towards integrated and sustainable control and a word of caution. Parasitology 2009, 136:1859-1874

7. WHO: Schistosomiasis: Progress Report 2001-2011 and Strategic Plan 2012-2020. Geneva: World Health Organization; 2013.

8. Gryseels B, Polman K, Clerinx J, Kestens L: Human schistosomiasis. Lancet 2006, 368:1106-1118.

9. King $\mathrm{CH}$ : Parasites and poverty: the case of schistosomiasis. Acta Trop 2010, 113:95-104.

10. Utzinger J, N'Goran EK, Caffrey CR, Keiser J: From innovation to application: social-ecological context, diagnostics, drugs and integrated control of schistosomiasis. Acta Trop 2011, 120(Suppl 1):S121-S137.

11. N'Goran EK, Yapi YG, Bellec C, Sellin B: Données préliminaires sur les variations journalières des densités cercariennes de Schistosoma mansoni dans deux foyers forestiers de schistosomose intestinale de la région de Man (Côte d'Ivoire). Bulletin de Médecine Traditionnelle et Pharmacopée 1989, 3:117-127.

12. Lambertucci JR, Serufo JC, Gerspacher-Lara R, Rayes AA, Teixeira R, Nobre V, Antunes CM: Schistosoma mansoni: assessment of morbidity before and after control. Acta Trop 2000, 77:101-109.

13. King CH, Dickman K, Tisch DJ: Regauging the cost of chronic helminthic infection: meta-analysis of disability-related outcomes in endemic schistosomiasis. Lancet 2005, 365:1561-1569.

14. Al-Shamiri AH, Al-Taj MA, Ahmed AS: Prevalence and co-infections of schistosomiasis/hepatitis $B$ and $C$ viruses among school children in an endemic area in Taiz, Yemen. Asian Pac J Trop Med 2011, 4:404-408.

15. Mazigo HD, Nuwaha F, Wilson S, Kinung'hi SM, Morona D, Waihenya R, Heukelbach J, Dunne DW: Epidemiology and interactions of human immunodeficiency virus-1 and Schistosoma mansoni in sub-Saharan Africa. Infect Dis Poverty 2013, 2:2.

16. Kinung'hi SM, Magnussen P, Kaatano GM, Kishamawe C, Vennervald BJ: Malaria and helminth co-infections in school and preschool children: a cross-sectional study in Magu district, north-western Tanzania. PLoS One 2014, 9:e86510.

17. Raso G, Matthys B, N'Goran EK, Tanner M, Vounatsou P, Utzinger J: Spatial risk prediction and mapping of Schistosoma mansoni infections among schoolchildren living in western Côte d'Ivoire. Parasitology 2005, 131:97-108.

18. Pinot de Moira A, Fulford AJ, Kabatereine NB, Ouma JH, Booth M Dunne DW: Analysis of complex patterns of human exposure and immunity to schistosomiasis mansoni: the influence of age, sex, ethnicity and IgE. PLoS Negl Trop Dis 2010, 4:e820. 
19. Poda JN, Wango SP, Sorgho H, Dianou D: Évolution récente des schistosomoses dans le complexe hydroagricole du Sourou au Burkina Faso. Bull Soc Pathol Exot 2004, 97:15-18.

20. Enk MJ, Amaral GL, Costa e Silva MF, Silveira-Lemos D, Teixeira-Carvalho A, Martins-Filho OA, Correa-Oliveira R, Gazinnelli G, Coelho PMZ, Massara CL: Rural tourism: a risk factor for schistosomiasis transmission in Brazil. Mem Inst Oswaldo Cruz 2010, 105:537-540.

21. McCreesh N, Booth $\mathrm{M}$ : Challenges in predicting the effects of climate change on Schistosoma mansoni and Schistosoma haematobium transmission potential. Trends Parasitol 2013, 29:548-555.

22. WHO: Prevention and control of schistosomiasis and soil-transmitted helminthiasis: report of a WHO expert committee. WHO Tech Rep Ser 2002, 912:1-57

23. WHO: Schistosomiasis: population requiring preventive chemotherapy and number of people treated in 2010. Wkly Epidemiol Rec 2012, 87:37-44.

24. Doumenge J, Mott K, Cheung C, Villenave D, Chapuis O, Perrin MF Reaud-Thomas G: Atlas of the Global Distribution of Schistosomiasis. Bordeaux: Presses Universitaires de Bordeaux; 1987.

25. N'Goran EK, Utzinger J, Traoré M, Lengeler C, Tanner M: Identification rapide par questionnaire des principaux foyers de bilharziose urinaire au centre de la Côte d'Ivoire. Med Trop 1998, 58:253-260.

26. Utzinger J, N'Goran EK, Ossey YA, Booth M, Traoré M, Lohourignon KL, Allangba A, Ahiba LA, Tanner M, Lengeler C: Rapid screening for Schistosoma mansoni in western Côte d'lvoire using a simple school questionnaire. Bull World Health Organ 2000, 78:389-398.

27. N'Guessan NA, Acka CA, Utzinger J, N'Goran EK: Identification des régions à haut risque de schistosomoses en Côte d'Ivoire. Bull Soc Pathol Exot 2007, 100:119-123.

28. Tchuem Tchuenté LA, N'Goran EK: Schistosomiasis and soil-transmitted helminthiasis control in Cameroon and Côte d'Ivoire: implementing control on a limited budget. Parasitology 2009, 136:1739-1745

29. Chammartin F, Hürlimann E, Raso G, N'Goran EK, Utzinger J, Vounatsou P. Statistical methodological issues in mapping historical schistosomiasis survey data. Acta Trop 2013, 128:345-352.

30. Utzinger J, N'Goran EK, N'Dri A, Lengeler C, Tanner M: Efficacy of praziquantel against Schistosoma mansoni with particular consideration for intensity of infection. Trop Med Int Health 2000, 5:771-778.

31. Raso G, N'Goran EK, Toty A, Luginbühl A, Adjoua CA, Tian-Bi NT, Bogoch II, Vounatsou P, Tanner M, Utzinger J: Efficacy and side effects of praziquantel against Schistosoma mansoni in a community of western Côte d'Ivoire. Trans R Soc Trop Med Hyg 2004, 98:18-27.

32. Katz N, Chaves A, Pellegrino J: A simple device for quantitative stool thick smears technique in schistosomiasis mansoni. Rev Inst Med Trop São Paulo 1972, 14:397-400.

33. Knopp S, Becker SL, Ingram KJ, Keiser J, Utzinger J: Diagnosis and treatment of schistosomiasis in children in the era of intensified control. Expert Rev Anti-Infect Ther 2013, 11:1237-1258.

34. Utzinger J, N'Goran EK, Esse Aya CM, Acka Adjoua C, Lohourignon KL, Tanner M, Lengeler C: Schistosoma mansoni, intestinal parasites and perceived morbidity indicators in schoolchildren in a rural endemic area of western Côte d'Ivoire. Trop Med Int Health 1998, 3:711-720.

35. Keiser J, N'Goran EK, Traoré M, Lohourignon KL, Singer BH, Lengeler C, Tanner M, Utzinger J: Polyparasitism with Schistosoma mansoni, geohelminths, and intestinal protozoa in rural Côte d'Ivoire. J Parasitol 2002, 88:461-466.

36. Beck-Wörner C, Raso G, Vounatsou P, N'Goran EK, Rigo G, Parlow E, Utzinger J: Bayesian spatial risk prediction of Schistosoma mansoni infection in western Côte d'Ivoire using a remotely-sensed digital elevation model. Am J Trop Med Hyg 2007, 76:956-963.

37. Matthys B, Tschannen AB, Tian-Bi NT, Comoe H, Diabaté S, Traoré M, Vounatsou P, Raso G, Gosoniu L, Tanner M, Cissé G, N'Goran EK, Utzinger J: Risk factors for Schistosoma mansoni and hookworm in urban farming communities in western Côte d'Ivoire. Trop Med Int Health 2007, 12:709-723.

38. Utzinger J, N'Goran EK, N'Dri A, Lengeler C, Xiao SH, Tanner M: Oral artemether for prevention of Schistosoma mansoni infection: randomised controlled trial. Lancet 2000, 355:1320-1325

39. Bonfoh B, Raso G, Koné I, Dao D, Girardin O, Cissé G, Zinsstag J, Utzinger J, Tanner M: Research in a war zone. Nature 2011, 474:569-571.

40. Montresor A, Engels D, Ramsan M, Foum A, Savioli L: Field test of the 'dose pole' for praziquantel in Zanzibar. Trans $R$ Soc Trop Med Hyg 2002, 96:323-324.
41. Murray CJL, Vos T, Lozano R, Naghavi M, Flaxman AD, Michaud C, Ezzati M, Shibuya K, Salomon JA, Abdalla S, Aboyans V, Abraham J, Ackerman I, Aggarwal R, Ahn SY, Ali MK, Al Mazroa MA, Alvarado M, Anderson HR, Anderson LM, Andrews KG, Atkinson C, Baddour LM, Bahalim AN, Barker-Collo S, Barrero LH, Bartels DH, Basáñez M-G, Baxter A, Bell ML, et al: Disability-adjusted life years (DALYs) for 291 diseases and injuries in 21 regions, 1990-2010: a systematic analysis for the Global Burden of Disease Study 2010. Lancet 2012, 380:2197-2223.

42. WHO: Accelerating Work to Overcome the Global Impact of Neglected Tropical Diseases: A Roadmap for Implementation. Geneva: World Health Organization; 2012.

43. de Vlas SJ, Gryseels B: Underestimation of Schistosoma mansoni prevalences. Parasitol Today 1992, 8:274-277.

44. Utzinger J, Booth M, N'Goran EK, Müller I, Tanner M, Lengeler C: Relative contribution of day-to-day and intra-specimen variation in faecal egg counts of Schistosoma mansoni before and after treatment with praziquantel. Parasitology 2001, 5:537-544.

45. Booth M, Vounatsou P, N'Goran EK, Tanner M, Utzinger J: The influence of sampling effort and the performance of the Kato-Katz technique in diagnosing Schistosoma mansoni and hookworm co-infections in rural Côte d'Ivoire. Parasitology 2003, 127:525-531.

46. Enk MJ, Lima ACL, Drummond SC, Schall VT, Coelho PMZ: The effect of the number of stool samples on the observed prevalence and the infection intensity with Schistosoma mansoni among a population in an area of low transmission. Acta Trop 2008, 108:222-228.

47. Colley DG, Binder S, Campbell C, King CH, Tchuem Tchuenté LA, N'Goran EK, Erko B, Karanja DM, Kabatereine NB, van Lieshout L, Rathbun S: A five-country evaluation of a point-of-care circulating cathodic antigen urine assay for the prevalence of Schistosoma mansoni. Am J Trop Med Hyg 2013, 88:426-432.

48. WHO: World Health Organization: The World Health Assembly Resolution (WHA 54.19). Geneva: World Health Organization; 2001. Available at: http:// www.who.int/neglected_diseases/mediacentre/WHA_54.19_Eng.pdf; accessed: 20 October 2014

49. Rollinson D, Knopp S, Levitz S, Stothard JR, Tchuem Tchuenté LA, Garba A, Mohammed KA, Schur N, Person B, Colley DG, Utzinger J: Time to set the agenda for schistosomiasis elimination. Acta Trop 2013, 128:423-440.

doi:10.1186/1471-2458-14-1290

Cite this article as: Assaré et al:: Sustaining control of schistosomiasis mansoni in moderate endemicity areas in western Côte d'Ivoire: a SCORE study protocol. BMC Public Health 2014 14:1290.

\section{Submit your next manuscript to BioMed Central and take full advantage of:}

- Convenient online submission

- Thorough peer review

- No space constraints or color figure charges

- Immediate publication on acceptance

- Inclusion in PubMed, CAS, Scopus and Google Scholar

- Research which is freely available for redistribution

Submit your manuscript at www.biomedcentral.com/submit
C) Biomed Central 